\title{
Cytogenetic analysis on the holocentric chromosomes of the cabbage aphid Brevicoryne brassicae
}

\author{
Sara Giannini ${ }^{1}$, Davide Bizzaro ${ }^{2}$, Mauro Mandrioli ${ }^{3}$ and Gian Carlo Manicardi ${ }^{1}{ }^{\text {* }}$ \\ ${ }^{1}$ Dipartimento di Scienze Agrarie, Università di Modena e Reggio Emilia, Via Kennedy 17, 42100 Reggio Emilia. \\ 2 Istituto di Biologia e Genetica, Università di Ancona, Via Brecce Bianche, 60131 Ancona. \\ ${ }^{3}$ Dipartimento di Biologia Animale, Università di Modena e Reggio Emilia, Via Campi 213/D, 41100 Modena.
}

\begin{abstract}
Chromatin organization in the holocentric chromosomes of the aphid Brevicoryne brassicae has been investigated at a cytological level after C-banding, NOR, Giemsa, DAPI and $\mathrm{CMA}_{3}$ staining. C-banding technique showed the presence of heterochromatic bands on both telomeres of the two X chromosomes, whereas only the longest pair of autosomes show distinct intercalary C-positive bands. Moreover, silver staining and fluorescent in situ hybridization (FISH) with a $28 \mathrm{~S}$ rDNA probe localized rDNA genes on one telomere of each $\mathrm{X}$ chromosome; these are the only brightly fluorescent $\mathrm{C}$-positive regions revealed after $\mathrm{CMA}_{3}$ staining, whereas all other heterochromatic bands are DAPI positive.
\end{abstract}

Key words: Aphid, Cytogenetic, Holocentric chromosomes, Heterochromatin, AgNORs, FISH.

\section{INTRODUCTION}

Classic and molecular cytogenetics provides an integrated approach for a structural, functional and evolutionary analysis of chromosomes. Up to date, almost all studies concerning chromatin structure and organization have concentrated upon monocentric chromosomes, whereas data concerning holocentric ones are scanty.

Aphids, because of the easiness with which mitotic chromosomes can be obtained from embryonic tissues, represent a useful model for a better understanding of the architecture of holocentric chromosomes, in order to work out the differences or similarities in respect to monocentric ones. The identification of chromosomal markers in organisms possessing holocentric chromosomes is extremely important since the lack of a primary constriction, together with the

\footnotetext{
* Corresponding author: fax +39522 301482; e-mail: manicardi.giancarlo@unimo.it
}

difficult in obtaining a clear-cut banding pattern, have greatly hampered cytogenetic studies in species possessing such a peculiar chromatin organization (BLACKMAN 1987; HALES et al. 1997; MANICARDI et al. 2002). The interest of a cytogenetic approach towards aphid chromosomes is emphasized by the consideration that information regarding aphid genomes could be important not only from a scientific, but also from an economic point of view. Aphids are, in fact, lymph-sucking insects and they have serious implication for agriculture, not only in view of their parasitic action against crops, but also because they represent active vectors of crop viruses.

In this paper we present data regarding a cytogenetic analysis on Brevicoryne brassicae, a sup-sucking aphid widely distributed in temperate regions of the world where it may severely damage brassicaceous field crops by feeding and transmitting about 20 plant viruses (BLACKMAN and EASTOP 1984). 


\section{MATERIAL AND METHODS}

Brevicoryne brassicae specimens were collected from a field population living in a cabbage field near Modena. The aphids were successively reared on Brassicae oleracea plants in a controlled environment chamber maintained at $18^{\circ} \pm 2^{\circ}$ with a photoperiod L16:D8.

Chromosome preparations of parthenogenetic females were made by spreading embryo cells, as previously described by MANICARDI et al. (1996).

$\mathrm{C}$-banding treatment was performed according to SUMNER's technique (1972). After the treatments, some slides were stained with $5 \%$ Giemsa solution in
Soerensen buffer pH 6.8, for 10 min. Chromomycin $\mathrm{A}_{3}$ $\left(\mathrm{CMA}_{3}\right)$ staining was made in accordance to SCHWEIZER (1976), whereas 4'-6'-diamidino-2-phenylindole (DAPI) treatment was carried out as described by DONLON and MAGENIS (1983). Silver staining of nucleolar organizing regions (NORs) was performed following the technique of HOWELL and BLACK (1980).

DNA extraction from aphid embryos was carried out as described in MANDRIOLI et al. (1999a). The 28S rDNA probe was obtained by PCR amplification of $B$. brassicae genomic DNA carried out using two primers, F (5'-AACAAACAACCGATACGTTCCG) and R (5'CTCTGTCCGTTTACAACCGAGC), designed
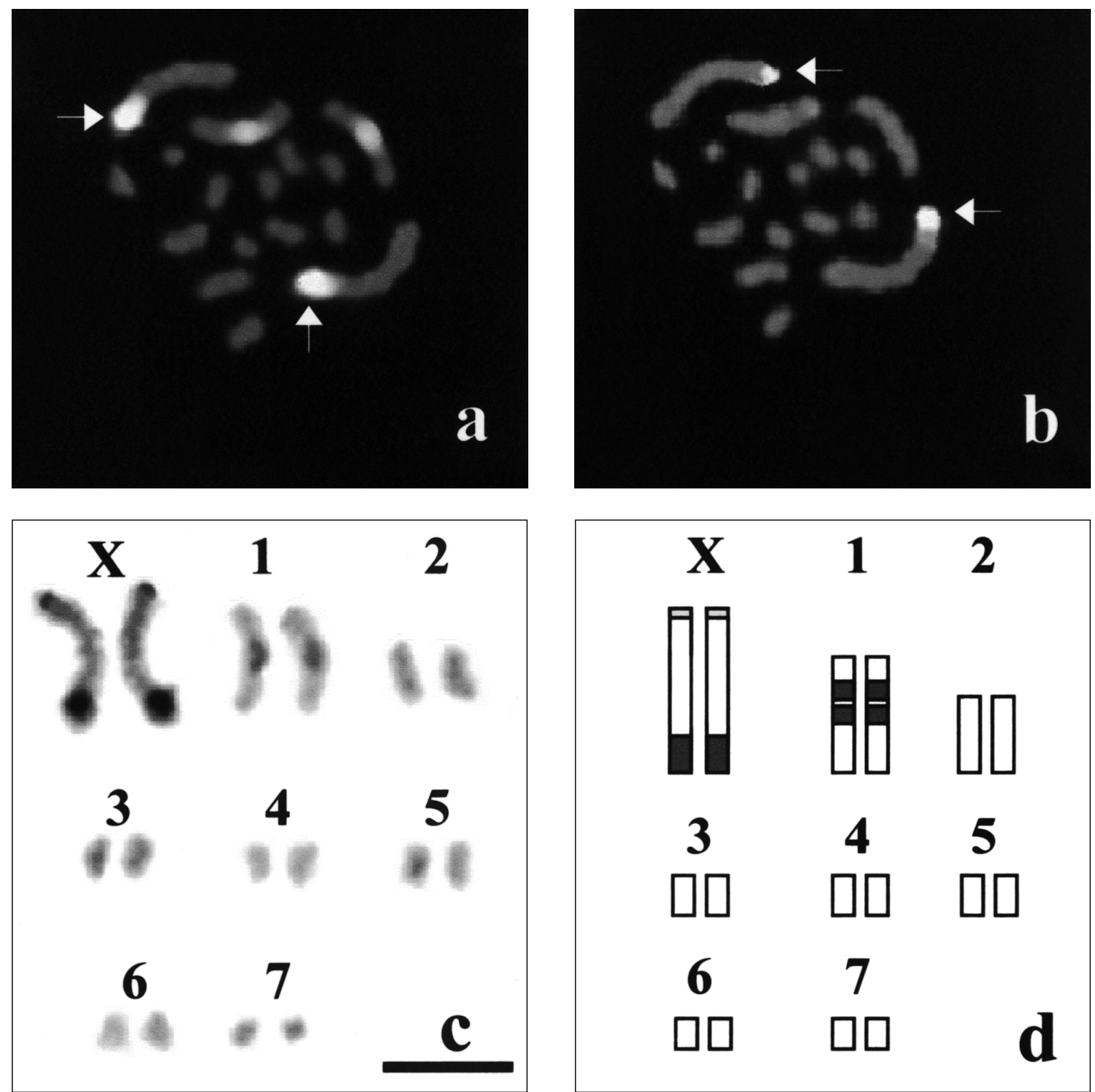

Fig. 1 - C-banded methaphase chromosomes of Brevicoryne brassicae females after DAPI (a), CMA $($ b) and Giemsa (c) staining, the idiogram (d) summarises C-banding pattern. Arrows indicate X chromosomes. Bar $10 \mu \mathrm{m}$. 
according to the coding $28 \mathrm{~S}$ sequence of the aphid Acyrthosiphon pisum (GenBank X66419) (AMAKO et al. 1996). The amplification mix contained $100 \mathrm{ng}$ genomic DNA, $1 \mu \mathrm{M}$ of each primer, $200 \mu \mathrm{M}$ dNTPs and 2 U of DyNAZyme II polymerase (Finnzymes Oy). The amplification was performed with a thermocycler Hybaid at an annealing temperature of $60^{\circ} \mathrm{C}$ for $1 \mathrm{~min}$ and extension at $72^{\circ} \mathrm{C}$ for $1 \mathrm{~min}$. Probe labelling and fluorescent in situ hybridisation (FISH) were performed according to BIZZARO et al. (1996).

\section{RESULTS}

B. brassicae metaphases, obtained from parthenogenetic females, revealed a chromosome number of $2 n=16$ (Fig. 1). C-banding technique showed telomeric bands on both X chromosomes, whereas, among autosomes, only the A1 couple had two C-positive intercalary bands (Fig. 1c).

Staining of C-banded chromosomes with fluorochromes evidenced that most of the B. brassicae heterochromatin was brightly fluorescent after DAPI staining and therefore AT rich (Fig. 1a), whereas only the smaller C-band located at one telomere of each $\mathrm{X}$ chromosome contained $\mathrm{CMA}_{3}$ positive, GC rich DNA (Fig. 1b).

The $\mathrm{CMA}_{3}$ positive $\mathrm{X}$ telomeres were also argentophilic after staining with $\mathrm{AgNO}_{3}$ (Fig. 2b) and intensely fluorescent after FISH experiments carried out utilizing a $28 \mathrm{~S} \mathrm{rDNA}$ sequence as a probe (Fig. 2a), demonstrating that these telomeres contained actively transcribed rDNA genes. A slight difference between homologous NORs was observed both after silver staining and FISH (Fig. 2). In addition to the NORs, silver staining

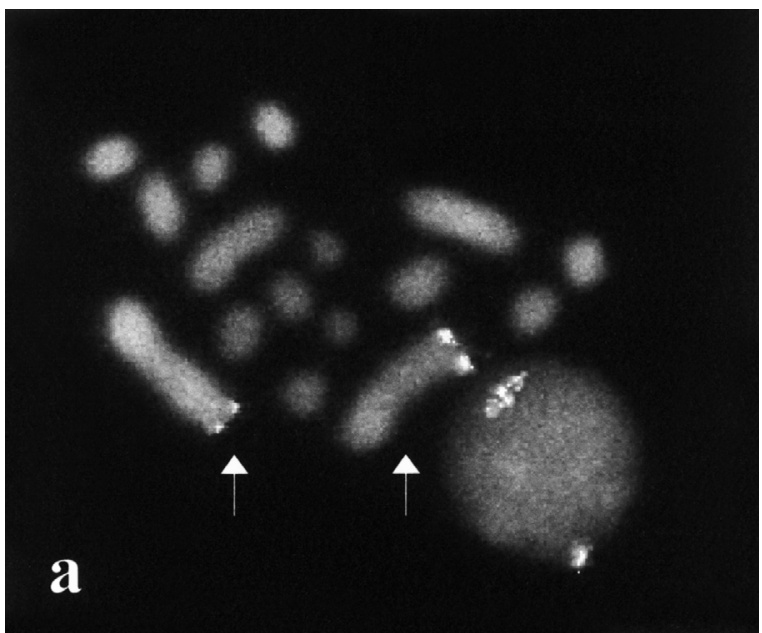

also revealed the presence of axial structures, running parallel along the chromatid axes, without point of intersection, as expected by the holocentric nature of aphid chromosomes (Fig. 2 b).

\section{DISCUSSION}

Currently, more than 4,000 aphid species has been described, but the chromosome number has only been reported for about $20 \%$ of these (GAUTAM et al. 1993).

The main objective of our study was to perform a cytogenetic analysis of $B$. brassicae genome, which could improve the knowledge of this pest crop species.

All the observed metaphase plates evidenced a chromosome number of $2 n=16$ which represents the typical diploid chromosome number of the species reported in the literature (COLLING 1955; PAgLiai 1962).

C-banding treatment allows a definitive identification of at least a portion of the homologues and this improves the construction of nonambiguous karyotype. Indeed, holocentric chromosomes lack primary conscription whereas attempts to identify homologous chromosomes only on the basis on their length can be misleading due to the phenomenon of allocyclia.

C-banding carried out on B. brassicae mitotic chromosomes revealed that heterochromatin was not equilocated on each chromosome. This pattern, observed in all the aphid species cytogenetically studied to date (for a review see MANICARDI et al. 2002), could be considered typical of

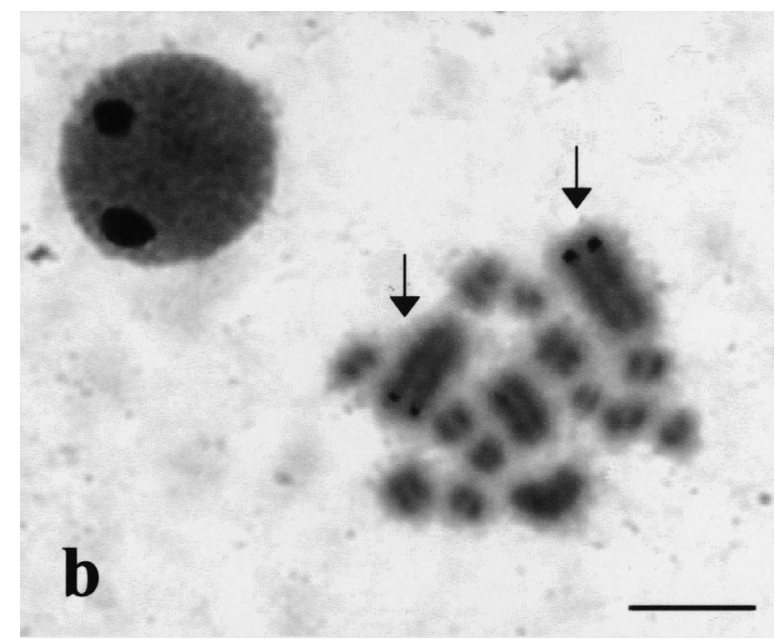

Fig. 2 - Localization of rDNA genes on B. brassicae mitotic chromosomes after FISH with a rDNA probe (a) and silver staining (b). Arrows indicate $\mathrm{X}$ chromosomes. Bar $10 \mu \mathrm{m}$. 
holocentric chromosomes and it differs from that observed on monocentric chromosomes, where the heterochromatic regions typically occupy specific zones of all chromosomes, corresponding to centromeres or sometimes telomeres (SCHWEIZER and LOIDL 1987).

The different response to $\mathrm{CMA}_{3}$ and DAPI staining after C-banding points out the heterogeneity of heterochomatic DNA composition in B. brassicae genome. In fact, GC-rich NOR-associated heterochromatin differs from all other heterochromatic bands that are characterised by ATrich DNAs. This pattern of heterochromatin heterogeneity seems to be a general characteristic of aphid chromatin since it has been described in all species investigated so far at a cytogenetic level (MANICARDI et al. 2002 and references within).

Silver staining of $B$. brassicae mitotic metaphases revealed two dots located on one telomere of each sex chromosome. This seems to be a highly conservative characteristic of aphid chromosomes, since the same NOR location has been described in almost all the species of aphids studied to date (KUZNETSOVA and GANDRABUR 1991; BLACKMAN and SPENCE 1996; MANICARDI et al. 1998, 2002).

Since male sex determination appears to be dependent on the capability of the $\mathrm{X}$ chromosomes to associate through the NOR bearing telomeres (ORLANDO 1974, 1983; BLACKMAN and HALES 1986), the necessity of maintaining the NORs in a well defined single site, could have fixed their location in the whole taxon.

Chromomycin $\mathrm{A}_{3}$ is a fluorochrome that preferentially forms stable complexes with double helix DNA rich in G-C sequences (BEHR et al. 1969). The overlapping between $\mathrm{CMA}_{3}$ and $\mathrm{AgNO}_{3}$ positive regions in $\mathrm{B}$. brassicae chromosomes can be attributed to a high G-C content which characterise rDNA genes (RITOSSA and SPIEgELMAN 1965; WALlaCE and BiRnSTIEL 1969). However, we should point out that, given the specificity of the silver nitrate stain for acid proteins associated with newly transcribed rRNA and not for rDNA, only the NORs that have been transcriptionally active in the preceding interphase are stained with $\mathrm{AgNO}_{3}$ (Howell 1977; SCHWARZACHER et al. 1978). Instead, $\mathrm{CMA}_{3}$, determines a positive fluorescence that is independent of the activity of the nucleolar organizing region (SCHMID and GuTTENBACH 1988). Since all the mitoses observed in B. brassicae were positive to both $\mathrm{CMA}_{3}$ and silver staining, we can conclude that all the NORs had undergone syn- thetic activity in the preceding interphase. Indeed, these treatments were carried out in rapidly proliferation embryonal cells. Moreover, since an appreciable level of heteromorphism between homologous NORs has been observed after both $\mathrm{CMA}_{3}$ and $\mathrm{AgNO}_{3}$ staining it is possible to hypothesise that the observed heteromorphism may be due to different distributions of rDNA genes between homologues and not to different levels of trascriptional activity. Heteromorphism at NORs, occasionally described in several organisms (SCHMID 1982, SANCHEZ et al. 1989; SUZUKI et al. 1990; ZURITA et al. 1997), has been repeatedly described in different aphid species (Blackman and SPENCE 1996, MANDRIOLI et al. 1998, 1999b, 2002).

\section{REFERENCES}

Amako D., Kwon O.Y. and IshiKawa H., 1996 Nucleotide sequence and presumed secondary structure of the $28 S$ rRNA of pea aphid: implication for diversification of insect $r R N A$. J. Mol. Evol., 43: 469-475.

BeHR W., Honikel K. and Hartmann G., 1969 Interaction of the RNA polymerase inbibitor chromomycin with DNA. Europ. J. Biochem., 9: 8292.

BiZZARO D., MANICARDI G.C. and BiANCHI U., 1996 - Chromosomal localization of a bighly repeated EcoRI DNA fragment in Megoura viciae (Homoptera, Aphididae) by nick-translation and fluorescence in situ bybridization. Chromosoma Res., 4: 392-396.

BLACKMAN R.L., 1987 - Reproduction, cytogenetics and development. In: Minsk A.K. and Harrewijn P. (Eds.): "Aphids: their biology, natural enemies and control”, Vol. A. pp. 163-195. Elsevier, Amsterdam.

BLACKMAN R.L. and EASTOP V.F., 1984 - Aphids on the world's crop. An identification guide. John Wiley \& Sons, pp. 248.

BLACKMAN R.L. and HaLES D.F., 1986 - Behaviour of the $X$ chromosomes during growth and maturation of parthenogenetic eggs of Amphorophora tuberculata (Homoptera, Aphididae), in relation to sex determination. Chromosoma, 94: 59-64.

BLACKMAN R.L. and SPENCE J.M., 1996 - Ribosomal DNA is frequently concentrated on only one $X$ chromosome in permanently apomictic aphids, but this does not inbibit male determination. Chromosome Res., 4: 314-320.

Colling A.W., 1955 - Aphid chromosomes. Nature, 176: 207-208. 
DONLON T.A. and MAGENIS R.E., 1983 - Metbyl green is a substitute for distamycin $A$ in the formation of distamycin A/DAPI C-bands. Hum. Genet., 65: 144-146.

Gautam D.C., Crema R. and Bonvicini Pagliai A.M., 1993 - Cytogenetic mechanism in aphids. Boll. Zool., 60: 233-244.

Hales D.F., Tomiuk J., Wohrmann K. and SunNUCKS P., 1997 - Evolutionary and genetic aspects of aphid biology: A review. Eur. J. Entomol., 94: $1-55$.

HOWELL W.M., 1977 - Visualization of ribosomal gene activity: silver stains proteins associated with rRNA transcribed from oocyte chromosomes. Chromosoma, 62: 361-367.

HOWELL W.M. and BLACK D.A., 1980 - Controlled silver-staining of nucleolus organizer regions with a protective colloidal developer: a 1 step-method. Experientia, 36: 1014-1015.

KuZNETSOVA V. and GANDRABUR S.I., 1991 - Nucleolar organizing regions in aphid chromosomes. Tsitologya (USSR), 33: 41-47.

Mandrioli M., Bizzaro D., Manicardi G.C., GiONGHI D., BASSOLI L. and BIANCHI U., 1999a - Cytogenetic and molecular characterization of a bighly repeated DNA sequence in the peach potato aphid Myzus persicae. Chromosoma, 108: 436442.

Mandrioli M., Manicardi G.C., Bizzaro D. and BIANCHI U., 1999b - NORs beteromorphism within a parthenogenetic lineage of the aphid Megoura viciae. Chromosome Res., 7: 157-162.

Manicardi G.C., Bizzaro D., Galli E. and BIANCHI U., 1996 - Heterochromatin heterogeneity in the bolocentric X chromatin of Megoura viciae (Homoptera, Aphididae). Genome, 39: 465 470.

Manicardi G.C., Bizzaro D., Mandrioli M., BIANCHI U. and CREMA R., 1998 - Occurrence of NOR beteromorphism on the two X chromosomes of different aphid species. In: Nieto Nafria J. M. and Dixon AFG (Eds.): "Aphids in natural and managed ecosystems”, pp. 91-95.

Manicardi G.C., Mandrioli M., Bizzaro D., BIANCHI U., 2002 - Cytogenetic and molecular analysis of heterochromatic areas in the bolocentric chromosomes of different aphid species. In: Sobti R.C., Obe G. and Athwal R.S. (Eds.), "Some aspects of chromosome structure and functions", pp. 47-56. Narosa Publishing House, New Delhi.

ORLANDO E., 1974 - Sex determination in Megoura viciae Bukton (Homoptera, Aphididae). Monit. Zool. Ital., 8: 61-70.
-, 1983 - Chromosomal abnormalities in male producing-eggs: a study in Megoura viciae (Homoptera, Apbidiae). Genetica, 62: 55-59.

PAGLiAi A.M., 1962 - La maturazione dell'uovo partenogenetico e dell'uovo anfigonico in Brevycorinae brassicae. Caryologia, 15: 537-544.

Ritossa F. and SPIEGELMAN S., 1965 - Localization of DNA complementary to ribosomal RNA in the nucleolus organizer region of Drosophila melanogaster. Proc. Nat. Acad. Sci. USA, 53: 737-745.

Sanchez A., Burgos M., Jimenez R. and Diaz DE LA GUARDIA R., 1989 - Quantitative analysis of silver staining on the nucleolar organizing regions in Eliomys quercinus. Genome, 32: 978-982.

SCHMID M., 1982 - Chromosome banding in Amphibia. VII. Analysis of the structure and variability of NORs in Anura. Chromosoma, 87: 327-344.

SCHMid M. and GutTEnBach M., 1988 - Evolutionary diversity of reverse $(R)$ fluorescent chromosome bands in vertebrates. Chromosoma, 97: 101-114.

Schwarzacher H.G., MikelsaAr A.V. and CONTRERAS N., 1978 - The nature of Ag-staining of nucleolus organizer regions. Cytogenet Cell Genet., 20: 24-39.

SCHWEIZER D., 1976 - Reverse fluorescent chromosome banding with chromomicyn and DAPI. Chromosoma, 58: 307-324.

SCHWEIZER D. and LOIDL J., 1987 - A model for beterochromatin disperse and the evolution of C-band patterns. In: Stahl A., LucianiJ., VagnerCapodano A.M (Eds.), "Chromosomes Today", vol. 9, pp. 61-74. Allen \& Unwin, London.

Sumner A.T., 1972 - A simple technique for demonstrating centromeric beterochromatin. Exp. Cell Res., 75: 304-306.

SuZuKi H., KuriHara Y., KaneHISA T. and MORIWAKI K., 1990 - Variation in the distribution of silver-stained nucleolar organizing regions on the chromosomes of the wild mouse Mus musculus. Mol. Biol. Evol., 7: 271-282.

WALlaCE H. and BieRntsiel M.L., 1969 - Ribosomal cistrons and the nucleolar organizer. Biochem. Biophys. Acta, 114: 296-310.

Zurita F., Sanchez A., Burgos M., Jimenez R. and DiAZ DE LA GUARDIA R., 1997 - Interchromosomal, intercellular and interindividual variability of NOR studied with silver staining and in situ bybridization. Heredity, 78, 229-234.

Received July 10, 2002; accepted September 20, 2002 